\title{
Aerobic oxidation of cyclohexene catalyzed by NiO/MCM-41 nanocomposites in the gas phase
}

\author{
AMIN EBADI $^{\mathrm{a}, *}$, MAJID MOZAFFARI $^{\mathrm{b}}$ and SANAZ SHOJAEI ${ }^{\mathrm{a}}$ \\ ${ }^{a}$ Department of Chemistry, Kazerun Branch, Islamic Azad University, Kazerun, Iran \\ ${ }^{b}$ Department of Chemistry, Shahrood Branch, Islamic Azad University, Shahrood, Iran \\ e-mail: ebadiamin88@yahoo.com
}

MS received 20 February 2014; revised 15 March 2014; accepted 19 March 2014

\begin{abstract}
The nanoparticles of $\mathrm{NiO}$ supported on mesoporous MCM-41 were synthesized and characterized with X-ray diffraction (XRD) and transmission electron microscopy (TEM). In this study, catalytic activities of the supported $\mathrm{NiO}$ nanoparticles for oxidation of cyclohexene to 2-cyclohexene-1-ol and 2-cyclohexene-1one with air in the gas phase were considered. These nanoparticles of NiO supported on mesoporous MCM-41 were effective catalysts in a temperature range of $220-310^{\circ} \mathrm{C}$ at $1 \mathrm{~atm}$ of air. Under these reaction conditions, the activity of the catalysts decreases in the following order: $5 \mathrm{wt} . \% \mathrm{NiO} / \mathrm{MCM}-41>7.5 \mathrm{wt} \% \mathrm{NiO} / \mathrm{MCM}-41$ $>2.5$ wt. \% NiO/MCM-41. With 5 wt.\% NiO supported on mesoporous MCM-41 and under our experimental conditions, the conversion percent of cyclohexene is $62.3 \%$ with $65.9 \%$ selectivity of 2-cyclohexene-1-ol + 2-cyclohexene-1-one and $12.2 \%$ cyclohexadiene at $280^{\circ} \mathrm{C}$. To achieve higher conversion of cyclohexene and better selectivity towards 2-cyclohexene-1-ol +2 -cyclohexene-1-one, factors such as reaction temperature, loading amount of nickel oxide and space velocity were studied, and optimized conditions were investigated.
\end{abstract}

Keywords. Oxidation; cyclohexene; NiO/MCM-41; 2-cyclohexene-1-ol; 2-cyclohexene-1-one

\section{Introduction}

Catalytic partial oxidation of hydrocarbons with air has important economic and industrial significances. Most hydrocarbon oxidations in the gas phase have shown low selectivity and conversion. In this regard, the main goal is to increase conversion and selectivity of these gas phase reactions. ${ }^{1-3}$ The allylic oxidation of olefin into $\alpha, \beta$-unsaturated ketones is an important transformation in natural product synthesis. ${ }^{4}$ In particular, the oxidation products of cyclohexene and their derivatives, viz. 2-cyclohexen-1-one, 1-methylcyclohex-1-en3 -one, etc., are important in organic synthesis due to the presence of a highly reactive carbonyl group, which is utilized in cycloaddition reactions. ${ }^{5-7}$ Great efforts have been devoted to the oxidation of cyclohexene in the past years. ${ }^{8-10}$

At the beginning of the 1990s, a new class of mesoporous materials composed of ordered silica was synthesized. These materials were first reported by Kato and co-workers, ${ }^{11}$ but rapid development began after introducing micelle templated silica by the group from Mobil Oil. ${ }^{12,13}$ Investigations into the synthesis, structural characterization and catalytic properties of the M41S family of periodic mesoporous silicas led to

*For correspondence the development of a major area of research into mesoporous molecular sieves, primarily due to the numerous applications in which these materials can be employed. ${ }^{14-16}$ The development of Ni-based catalysts (with $\mathrm{NiO}$ as the main active component) and their commercial application is promising, due to their high effectiveness in oxide hydrogenation and oxidation of hydrocarbons. ${ }^{17,18}$ In recent years, nanomaterials have attracted extensive interest for their unique properties in various fields in comparison to their bulk counterparts. ${ }^{19,20}$ In particular, nickel oxide $(\mathrm{NiO})$ has received a considerable amount of attention for its catalytic properties.

Oxide powders such as $\mathrm{NiO}$ and $\mathrm{CoO}$ are important catalysts in the chemical industry, and silica is usually preferred as a catalyst carrier since nickel or cobalt oxide layers deposited onto silica, exhibit good catalytic activity. ${ }^{21-23}$

$\mathrm{NiO}$, supported on a matrix, has been used in a wide variety of catalytic processes such as hydrodesulfurization (HDS) and hydrodechlorination (HDC), since Ni is inexpensive and functions as an active catalyst in such reactions. Relatively few studies, however, have been reported on applications of $\mathrm{NiO}$ inside mesoporous materials. In this work, the nano-sized MCM41 was synthesized and used as a support to disperse $\mathrm{NiO}$ catalyst and the resulting nanocomposite 
showed enhanced activity. The correlation of the structural activity of $\mathrm{NiO}$ and $\mathrm{NiO} / \mathrm{MCM}-41$ catalysts is well discussed in the present investigation. The nanocomposites of $\mathrm{NiO} / \mathrm{MCM}-41$ could effectively catalyze the oxidation of cyclohexene to 2-cyclohexene-1-ol and 2cyclohexene-1-one in the gas phase under atmospheric pressure.

\section{Experimental}

\subsection{Preparation of the catalysts}

Sodium silicate solution (25.5-28.5 wt. $\% \mathrm{SiO}_{2}$ and 7.58.5 wt. $\left.\% \mathrm{Na}_{2} \mathrm{O}, \mathrm{MERK}\right)$, cetyltrimethylammonium bromide (CTAB, 99\%, BDH), acetic acid glacial (100\%, analytical regent grade), nickel nitrate-hexahydrate, polyvinylpyrrolidone (PVP) and sodium hydroxide used in this work, all were of analytical grade.

Mesoporous MCM-41 silica was synthesized using a gel mixture with a composition of $4 \mathrm{SiO}_{2}$ : 1CTAB: 250 $\mathrm{H}_{2} \mathrm{O}$, which was described in the literature. ${ }^{24}$ A required amount of the CTAB was dissolved slowly in an appropriate amount of water and sodium silicate solution and stirred for $30 \mathrm{~min}$. By adding acetic acid drop by drop, $\mathrm{pH}$ of the mixture reached 10 and the obtained gel was placed in a polypropylene bottle and refluxed at $100{ }^{\circ} \mathrm{C}$ for $24 \mathrm{~h}$. After cooling and adjusting the $\mathrm{pH}$ at 10 with acetic acid the mixture was refluxed again for $24 \mathrm{~h}$ at $100{ }^{\circ} \mathrm{C}$. The $\mathrm{pH}$ adjustment and subsequent heating operations were repeated several times for 5 days and the obtained gel was filtered and washed with distilled water and dried in an oven to obtain a white MCM41 nanopowders. $\mathrm{NiO}$ nanoparticles were prepared with some modifications in the described procedure in the literature. ${ }^{25}$ Chemical preparation of $\mathrm{NiO}$ nanoparticles composed of two stages: the formation of nickel hydroxide precursor precipitate and subsequent transformation to $\mathrm{NiO}$ by thermal treatment. Nickel hydroxide precursor was prepared by slow dropwise addition of $0.1 \mathrm{M}$ sodium hydroxide $(\mathrm{NaOH})$ to the mixed solution of $0.1 \mathrm{M}$ nickel nitrate-hexahydrate and $0.5 \mathrm{~g}$ polyvinylpyrrolidone (PVP) as surfactant. The solution was vigorously stirred until the $\mathrm{pH}$ reached 7 . The resulting precipitate was filtered and washed thrice with distilled water and final washing was carried out using alcohol. The wet cake obtained after filtration was oven dried for $100^{\circ} \mathrm{C}$ overnight. The ovendried cake was heated at $450^{\circ} \mathrm{C}$ for $3 \mathrm{~h}$ to form $\mathrm{NiO}$ nanoparticle.

NiO/MCM-41 catalysts were finally prepared via simple solid-state dispersion (SSD) method by mixing different amounts of $\mathrm{NiO}$ nanoparticles with required nano-sized mesoporous MCM-41 in a minimum quantity of ethanol. The mixture was dried in an oven at $100^{\circ} \mathrm{C}$ overnight followed by calcination at $450^{\circ} \mathrm{C}$ for $3 \mathrm{~h}$.

\subsection{Experimental procedure}

A vertical fixed-bed glass reactor of $9 \mathrm{~cm}$ length and internal diameter of $1.5 \mathrm{~cm}$ operating at atmospheric pressure was utilized for the catalytic oxidation of cyclohexene. About $1 \mathrm{~g}$ of the catalyst sample with 60 80 mesh was placed on a sinter glass and fed with a $50 \mathrm{~mL}$ cyclohexene syringe by the automatic injector (Fresenius injectomats) at the desired temperature. The reactor was placed inside a temperature-controlled heating jacket with a thermocouple at the centre of the catalyst bed. The liquid product was collected by passing the hot gases through a water-cool condenser. The range of reaction temperature was $220-310^{\circ} \mathrm{C}$, space velocity of $2878-3176 \mathrm{~h}^{-1}$ (air was injected at $30 \mathrm{~mL} / \mathrm{min}$ velocity and cyclohexene at $1.5-2.5 \mathrm{~mL} / \mathrm{h}$ velocity) under $1 \mathrm{~atm}$ pressure. The reaction time was $3 \mathrm{~h}$ and a dual-channel (Shimadzu Model 8A) gas chromatograph (GC) was used online for analyzing the product.

\subsection{Structural characterization}

The powder x-ray diffraction (XRD) patterns were recorded on a Bruker Advance D8 Diffractometer with $\mathrm{Cu} K \alpha$ radiation $(\lambda=0.154 \mathrm{~nm})$. The TEM measurements were performed on a Philips CM 200 FEG/HRTEM (high-resolution transmission electron microscope) instrument operating at $200 \mathrm{Kv}$. Products were analyzed by a GC, Shimadzu $8 \mathrm{~A}$, using authentic samples equipped with a TCD detector using OV17, Propak-N, packed ( $2 \mathrm{~m}$ ) columns and Helium as the carrier gas. GC-MS analysis of the products was performed with the GC-MS model of ThermoquestFinnigan Trace, equipped with a DB-1 fused silica column (with a length of $60 \mathrm{~m}$ and internal diameter of $0.25 \mathrm{~mm}$ and film thickness of $0.25 \mu \mathrm{m}$ ) with helium as the carrier gas.

\section{Results and Discussion}

\subsection{Characterization of the catalysts}

XRD patterns of the samples are shown in figure 1 . The very intense peak appeared at low angle $(2 \theta=$ 2.55 ) on the figure $1 \mathrm{a}$ is assigned to reflections at (100) and two other additional picks with low intensities at 


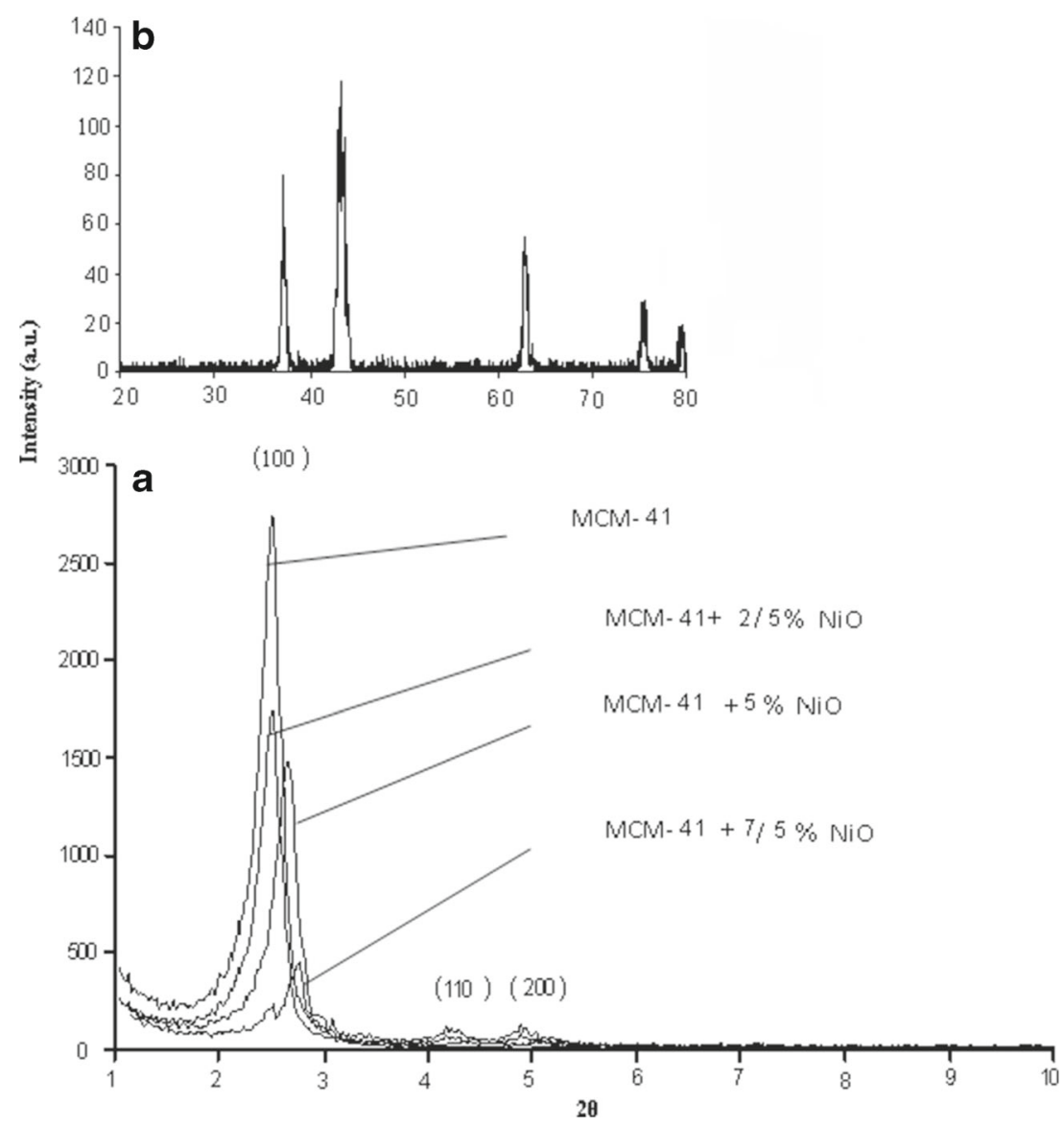

Figure 1. XRD patterns of samples (a) MCM-41 and NiO/MCM-41 (b) $\mathrm{NiO}$ nanoparticles.

(110) and (200) reflections indicate the regular pore structure of MCM-41 and can be attributed to quasitwo-dimensional hexagonal lattice of MCM-41.12 On dispersing $\mathrm{NiO}$ over MCM-41, a decrease in the peak intensity of the characteristic (100) plan is predominant, while at higher $\mathrm{NiO}$ loading samples, the peaks of (110) and (200) planes tend to merge with the base line. Decrease in the intensity can be attributed to the pores covering effects that reduce the scattering contrast between the pores and the framework of MCM-41 sample. It may also indicate a distortion of the long-range ordering of the mesoporous structure and/or badly built hexagonal array.

All these diffraction peaks in figure $1 \mathrm{~b}$, including not only the peak positions appearing at $37.28^{\circ}, 43.28^{\circ}$, $62.88^{\circ}, 75.28^{\circ}$ and $79.48^{\circ}$, but also their lattice parameters, are well consistent with that of the standard JCPDS Card No. 04-0835 for the standard spectrum of pure and cubic NiO. ${ }^{26,27}$ The results indicate that the products are nano-NiO crystal of cubic structure with high purity. It is seen in figure 1 that these characteristic diffraction peaks in the pattern have a markedly broadening effect. According to the Debye-Scherrer's equation:

$$
D=k \lambda / \beta \cos \theta
$$

where $D$ is the average crystallite size, $k$ is a constant equal to $0.9, \lambda$ is the $\mathrm{x}$-ray wavelength equal to $0.15406 \mathrm{~nm}$ and $\beta$ is the half-peak width, the mean crystallite size of the as-synthesized products calculated according to this equation is about $21 \mathrm{~nm}$.

Figure 2 shows UHTEM images of as-prepared pure MCM-41 and 5\%NiO/MCM-41. The ordered hexagonal pore arrangements of these two samples were clearly visible and the pores size and the thickness of the wall were estimated in the range of about $2-3 \mathrm{~nm}$ and $1 \mathrm{~nm}$, respectively. The images indicate that the hexagonal mesostructures of MCM-41 have not been affected by loading $\mathrm{NiO}$ nanoparticles.

Specific surface area measured with BET method was $1081 \mathrm{~m}^{2} / \mathrm{g}$ for MCM-41, $1022 \mathrm{~m}^{2} / \mathrm{g}$ for $5 \mathrm{wt} . \%$ $\mathrm{NiO} / \mathrm{MCM}-41$ and $915 \mathrm{~m}^{2} / \mathrm{g}$ for 7.5 wt.\% NiO/MCM41. 


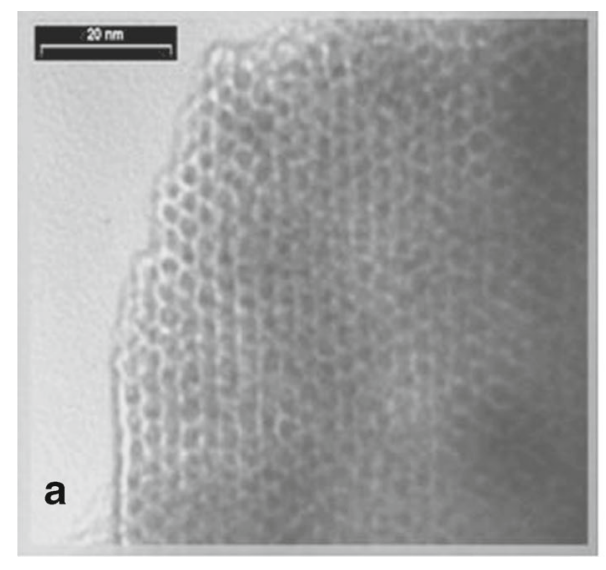

Figure 2. TEM images of samples (a) MCM-41 (b) 5\% NiO/MCM-41.

\subsection{Air oxidation of cyclohexene}

Cyclohexene was oxidized with air to 2-cyclohexene1 -ol and 2-cyclohexene-1-one at $62.3 \%$ conversion and $65.9 \%$ selectivity in the presence of $5 \mathrm{wt} . \% \mathrm{NiO}$ supported on mesoporous MCM-41 when this reaction proceeds under atmospheric pressure at $280^{\circ} \mathrm{C}$. This is a relatively mild system for industry. Another major product was obtained by dehydrogenation of cyclohexene. In this regard, $12.2 \%$ of cyclohexadiene was formed. The by-products of the reaction were 2-cyclohexene1-hydroperoxide, cyclohexadiene, $\mathrm{CO}$ and $\mathrm{CO}_{2}$. The product distribution for $5 \% \mathrm{NiO} / \mathrm{MCM}-41$ nanocomposite is summarized in table 1 . Selvam et al. ${ }^{28}$ reported that with $\mathrm{Cr} / \mathrm{MCM}-41$ molecular sieve catalyst and in the liquid phase a conversion of around $51.1 \%$ with $76.3 \%$ selectivity towards 2-cyclohexene-1-one was obtained. They also concluded that 2-cyclohexene-1one was obtained as the major product. In another report, Dias and co-workers ${ }^{29}$ used metalloporphyrin catalysts (FeTPPCl, MnTPPCl and CoTPP) supported

Table 1. Product distribution for cyclohexene partial oxidation by air at $\mathrm{T}=280^{\circ} \mathrm{C}, \mathrm{P}=1 \mathrm{~atm}$, space velocity $=$ $3027 \mathrm{~h}^{-1}$ and catalyst $5 \mathrm{wt} . \% \mathrm{NiO} / \mathrm{MCM}-41$.

\begin{tabular}{lc}
\hline Product $^{\mathrm{a}}$ & Selectivity (\%) \\
\hline 2-Cyclohexene-1-hydroperoxide & 8.9 \\
2-Cyclohexene-1-ol & 29.8 \\
2-Cyclohexene-1-one & 36.1 \\
$\mathrm{CO}_{2}$ & 3.6 \\
Cyclohexadiene & 12.2 \\
$\mathrm{CO}$ & 6.6 \\
Methanol & 0.8 \\
Ethanol & 0.7 \\
Phenol & 0.6 \\
5-Hexen 1 al & 0.5 \\
\hline
\end{tabular}

${ }^{\mathrm{a}}$ Only products with $\geq 0.5 \%$ selectivity are shown.

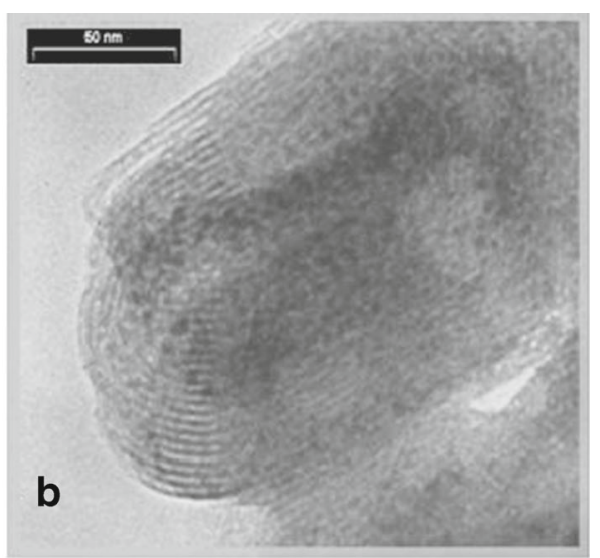

on MCM-41 in the cyclohexene oxidation reaction. They concluded that FeTPPCl/MCM-41 presented the highest conversion (25.8\%).

Experimental tests proved that in absence of the catalysts, oxidation of cyclohexene is negligible and unsupported mesoporous MCM-41 has shown lower catalytic activity than the supported catalyst.

When the reaction was catalyzed with mesoporous MCM-41 without any $\mathrm{NiO}$, the reaction yield and conversion reduced considerably compared with $\mathrm{NiO}$ supported on mesoporous MCM-41. This showed that the active species responsible for oxidation of cyclohexene were loaded $\mathrm{NiO}$ on the support, since, with the use of only mesoporous MCM-41 as a catalyst, no reactivity and activity towards cyclohexene oxidation were observed.

\subsection{The influences of the loading amount of nickel oxide on cyclohexene oxidation reaction}

For investigating the effect of the loading amount of nickel oxide on mesoporous MCM-41 upon yield of products, three catalysts were tested. In table 2, details of the conversion and selectivity of the products for each catalyst are shown. It was observed that maximum conversion and selectivity for 2-cyclohexene1-ol and 2-cyclohexene-1-one occured with the catalyst of 5 wt.\% $\mathrm{NiO}$. It is known that $\mathrm{NiO}$ nanoparticles can be highly dispersed on mesoporous MCM41 at 5 wt.\% loading. A drop in conversion of cyclohexene and selectivity for 2-cyclohexene-1-ol and 2-cyclohexene-1-one for the catalyst with higher loadings than 5 wt. $\%$ is possibly due to a distortion of the long-range ordering of the mesoporous structure and/or badly built hexagonal array and more reduction of the specific surface area of the catalyst. Under these reaction conditions, the order of 
Table 2. Effect of temperature on partial oxidation ${ }^{\text {a }}$ of cyclohexene by air.

\begin{tabular}{|c|c|c|c|c|c|c|c|}
\hline \multirow[b]{2}{*}{ Catalyst } & \multirow[b]{2}{*}{ Temperature $\left({ }^{\circ} \mathrm{C}\right)$} & \multirow[b]{2}{*}{ Conversion $(\%)$} & \multicolumn{5}{|c|}{ Selectivity products ${ }^{\mathrm{b}}(\%)$} \\
\hline & & & A & B & $\mathrm{C}$ & $\mathrm{D}$ & $\mathrm{E}$ \\
\hline $2.5 \% \mathrm{NiO} / \mathrm{MCM}-41$ & 220 & 18.2 & 20.7 & 20.2 & 15.3 & 10.8 & 29.1 \\
\hline $2.5 \% \mathrm{NiO} / \mathrm{MCM}-41$ & 250 & 37.4 & 15.3 & 22.6 & 19.4 & 11.5 & 27.6 \\
\hline $2.5 \% \mathrm{NiO} / \mathrm{MCM}-41$ & 280 & 48.9 & 11.4 & 28.3 & 21.7 & 12.1 & 22.7 \\
\hline $2.5 \% \mathrm{NiO} / \mathrm{MCM}-41$ & 310 & 66.8 & 6.8 & 19.9 & 14.6 & 11.8 & 43.0 \\
\hline $5 \% \mathrm{NiO} / \mathrm{MCM}-41$ & 220 & 24.8 & 18.5 & 27.4 & 22.7 & 9.8 & 17.7 \\
\hline $5 \% \mathrm{NiO} / \mathrm{MCM}-41$ & 250 & 40.6 & 12.5 & 31.7 & 25.4 & 11.5 & 14.9 \\
\hline $5 \% \mathrm{NiO} / \mathrm{MCM}-41$ & 280 & 62.3 & 8.9 & 36.1 & 29.8 & 12.2 & 10.2 \\
\hline $5 \% \mathrm{NiO} / \mathrm{MCM}-41$ & 310 & 80.6 & 4.5 & 28.4 & 21.2 & 13.7 & 28.4 \\
\hline 7.5\% NiO/MCM-41 & 220 & 21.8 & 20.4 & 24.6 & 19.8 & 10.1 & 21.3 \\
\hline $7.5 \% \mathrm{NiO} / \mathrm{MCM}-41$ & 250 & 36.4 & 14.9 & 29.2 & 23.6 & 11.4 & 16.8 \\
\hline $7.5 \% \mathrm{NiO} / \mathrm{MCM}-41$ & 280 & 54.2 & 10.1 & 32.2 & 25.9 & 11.9 & 15.7 \\
\hline 7.5\% NiO/MCM-41 & 310 & 71.8 & 6.9 & 25.5 & 18.1 & 12.6 & 33.1 \\
\hline MCM-41 & 220 & 9.4 & 53.2 & 2.1 & 1.3 & 5.6 & 34.9 \\
\hline MCM-41 & 250 & 16.8 & 37.8 & 8.7 & 5.8 & 11.7 & 33.3 \\
\hline MCM-41 & 280 & 23.5 & 19.4 & 13.5 & 9.9 & 17.2 & 36.9 \\
\hline MCM-41 & 310 & 30.4 & 9.3 & 13.6 & 10.1 & 19.4 & 44.6 \\
\hline
\end{tabular}

${ }^{\mathrm{a}}$ Catalyst $=\mathrm{X} \% \mathrm{NiO} / \mathrm{MCM}-41$ nanocomposites, catalyst weight $=1 \mathrm{~g}$, reaction time $=3 \mathrm{~h}, \mathrm{P}=1 \mathrm{~atm}$, rate of cyclohexene injection $=2 \mathrm{~mL} / \mathrm{h}$ and rate of air flow $=30 \mathrm{~mL} / \mathrm{min}$.

b $\mathrm{A}=2$-cyclohexene-1-hydroperoxide, $\mathrm{B}=2$-cyclohexene-1-one, $\mathrm{C}=2$-cyclohexene-1-ol, $\mathrm{D}=$ cyclohexadiene, $\mathrm{E}=\mathrm{CO}_{\mathrm{x}}$.

catalytic activities is as follows: 5 wt. $\% \mathrm{NiO} / \mathrm{MCM}-$ $41>7.5$ wt. $\% \mathrm{NiO} / \mathrm{MCM}-41>2.5$ wt. $\% \mathrm{NiO} /$ MCM-41.

\subsection{The influences of temperature on cyclohexene oxidation reaction}

Table 2 shows the effects of reaction temperature on the conversion percent of cyclohexene and selectivity of 2cyclohexene-1-ol and 2-cyclohexene-1-one. Considering the fact that selectivity is more important than the conversion percent, all three catalysts showed their best performance at $280^{\circ} \mathrm{C}$. Figure 3 shows the conversion percent of cyclohexene in the presence of various catalysts in different temperatures and figure 4 indicates the selectivity of product formation.

These studies showed that the rise in reaction temperature from $220^{\circ} \mathrm{C}$ to $310^{\circ} \mathrm{C}$ increased the conversion of cyclohexene and the highest value of the conversion was obtained when the reaction temperature was increased to $310^{\circ} \mathrm{C}$. As for the distribution of the products, with increasing reaction temperature from $220^{\circ} \mathrm{C}$ to $280^{\circ} \mathrm{C}$, the selectivity of 2-cyclohexene-1one and 2-cyclohexene-1-ol increased and reached its maximum in $280^{\circ} \mathrm{C}$, but the selectivities of 2cyclohexene-1-hydroperoxide decreased and reached

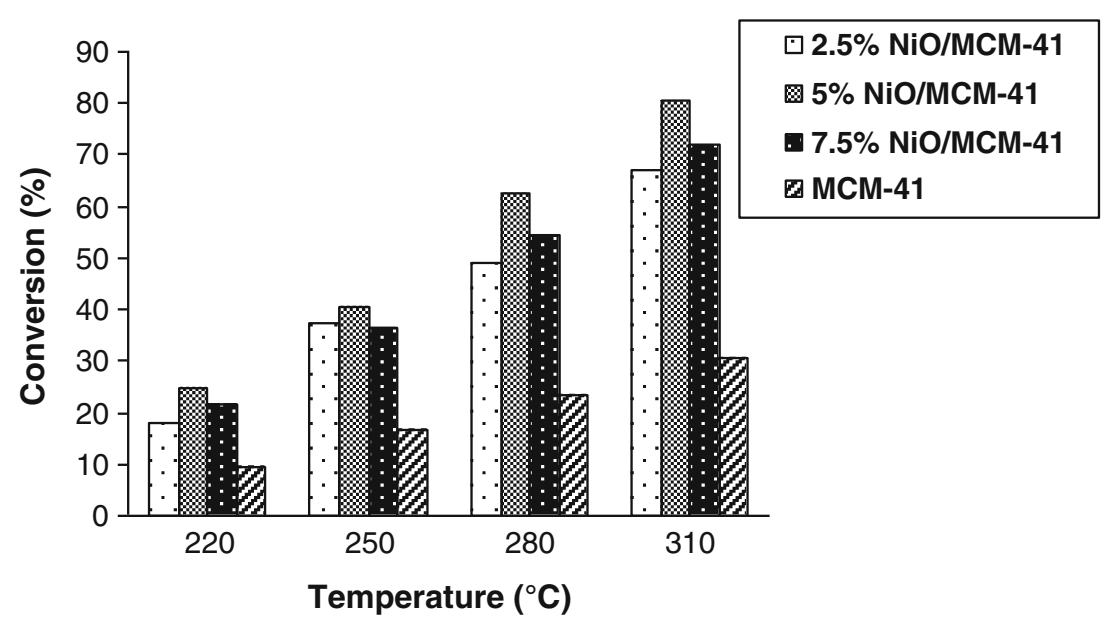

Figure 3. The diagram of cyclohexene conversion versus temperature. 


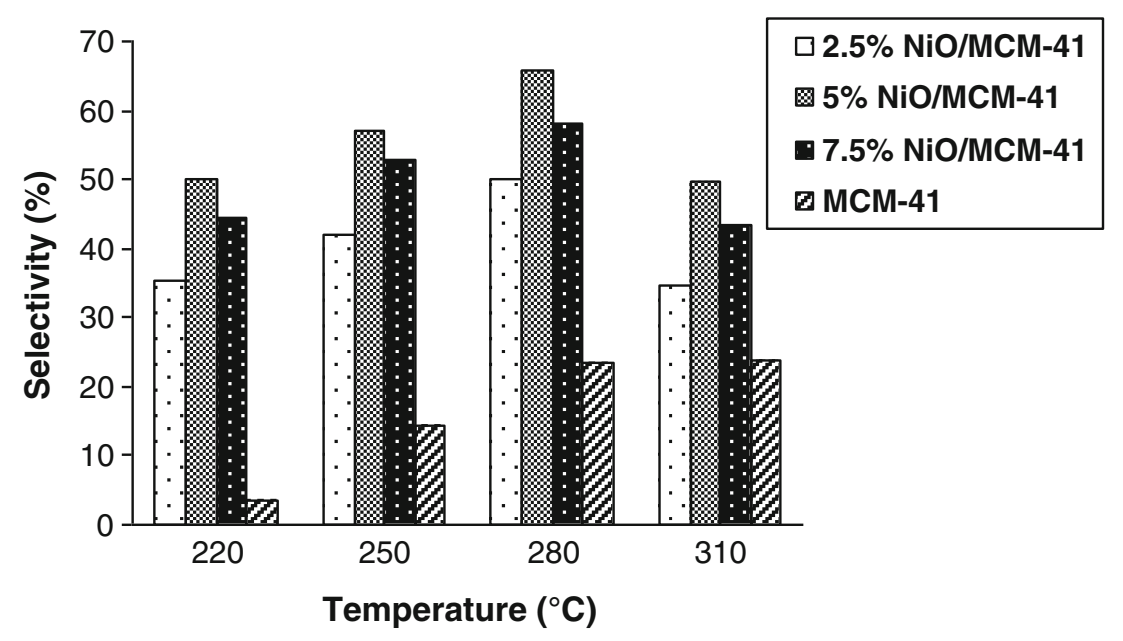

Figure 4. The changes of 2-cyclohexene-1-ol and 2-cyclohexene-1-one selectivity with respect to the reaction temperature in the presence of various catalysts.

its minimum in $310^{\circ} \mathrm{C}$. It is indicative of a free radical reaction pathway. ${ }^{30}$ When reaction temperature was increased from $280^{\circ} \mathrm{C}$ to $310^{\circ} \mathrm{C}$, selectivity of the 2cyclohexene-1-one and 2-cyclohexene-1-ol decreased considerably. In addition, at higher temperatures, more $\mathrm{CO}$ and $\mathrm{CO}_{2}$ were formed that were the products of complete oxidation. The reduction of selectivity at higher temperatures may be due to oxidative degradation of the products.

\subsection{The influences of space velocity on cyclohexene oxidation reaction}

Table 3 shows how cyclohexene conversion and selectivity of 2-cyclohexene-1-ol and 2-cyclohexene-1-one change with space velocity. Space velocity is a criterion for contact time of substrate with the catalyst. In space velocities higher than $3176 \mathrm{~h}^{-1}$ (rate of cyclohexene injection $=2.5 \mathrm{~mL} / \mathrm{h}$ and rate of air flow $=$ $30 \mathrm{~mL} / \mathrm{min}$ ), contact time of cyclohexene with catalyst

Table 3. Effect of space velocity on the conversion of cyclohexene and selectivity of 2-cyclohexene-1-one +2 cyclohexene-1-ol formation ${ }^{\mathrm{a}}$.

\begin{tabular}{lcc}
\hline Space velocity $\left(\mathrm{h}^{-1}\right)$ & Conversion $(\%)$ & Selectivity $(\%)$ \\
\hline 3837 & 35.2 & 34.4 \\
3176 & 44.9 & 47.1 \\
3027 & 62.3 & 65.9 \\
2878 & 73.7 & 35.3 \\
2217 & 43.7 & 30.9 \\
\hline
\end{tabular}

${ }^{\mathrm{a} C a t a l y s t}=5$ wt. $\%$ NiO/MCM-41 nanocomposite, $\mathrm{T}=$ $280{ }^{\circ} \mathrm{C}$, catalyst volume $\approx 1.5 \mathrm{~mL}$, catalyst weight $=1 \mathrm{~g}$, reaction time $=3 \mathrm{~h}, \mathrm{P}=1 \mathrm{~atm}$. was short and conversion percent and selectivity for the major products were low. However, in space velocities lower than $2878 \mathrm{~h}^{-1}$ (rate of cyclohexene injection $=$ $1.5 \mathrm{~mL} / \mathrm{h}$ and rate of air flow $=30 \mathrm{~mL} / \mathrm{min}$ ), the contact time seems too much; the main oxidation products are $\mathrm{CO}$ and $\mathrm{CO}_{2}$ and selectivity of 2-cyclohexene-1ol and 2-cyclohexene-1-one decreased. When the oxygen flow rate was lowered, the conversion percent of cyclohexene and selectivity for the major products is also decreased, i.e., for space velocity $2217 \mathrm{~h}^{-1}$ (rate of cyclohexene injection $=2 \mathrm{~mL} / \mathrm{h}$ and rate of air flow $=$ $20 \mathrm{~mL} / \mathrm{min}$ ). The best combination for high conversion percent and good selectivity for 2-cyclohexene-1-ol and 2-cyclohexene-1-one was obtained at $3027 \mathrm{~h}^{-1}$ space velocity (rate of cyclohexene injection $=2 \mathrm{~mL} / \mathrm{h}$ and rate of air flow $=30 \mathrm{~mL} / \mathrm{min}$ ). Therefore, contact time of substrate with catalyst seems an important factor for high conversion and specificity of the products.

\subsection{Discussion}

To explain how the oxidation occurred, based on the literatures ${ }^{30-32}$, it seems that oxidation of cyclohexene using $\mathrm{O}_{2}$ as oxidant proceeds via a classic Haber-Weiss radical-chain sequence mechanism as shown in scheme 1 .

According to the literature, ${ }^{33,34}$ the oxidation of cyclohexene with molecular oxygen initially forms 2cyclohexene-1-hydroperoxide as shown in scheme 1 (step a). 2-Cyclohexene-1-hydroperoxide is not stable and can form 2-cyclohexene-1-ol (step c) or decompose to 2-cyclohexene-1-ol and 2-cyclohexene-1-one in the presence of catalyst (step g). The conversion of cyclohexene is controlled by the rate of step a in scheme 1. 
Initiation:

(a)<smiles>O=C(O)C1C=CCCC1C(=O)O</smiles>

(b)

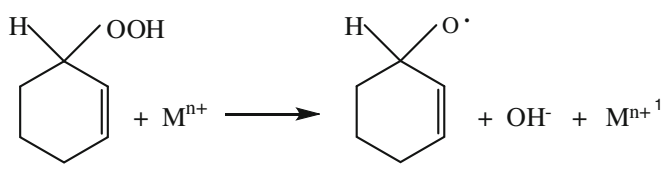

(c)

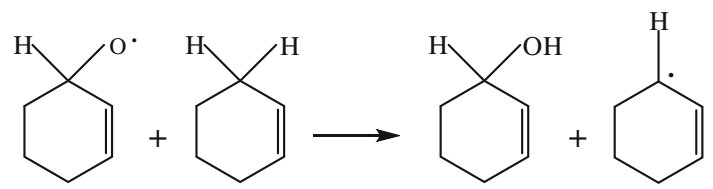

Propagation:

(d)

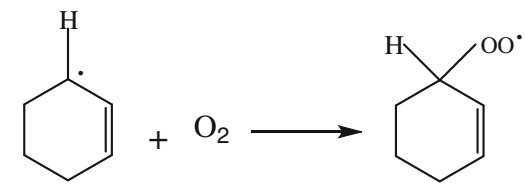

(e)

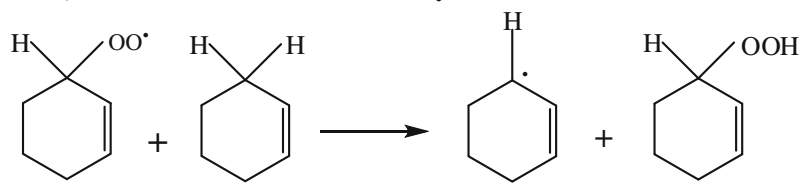

(f) $\mathrm{M}^{\mathrm{n}+1}+$

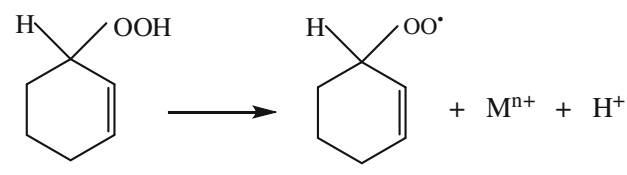

Termination:

(g)<smiles>OC1C=CCCC1</smiles><smiles>O=CC1C=CCCC1COOOC1CCCCC1</smiles><smiles>CCC[C+]1=CCCC(CC)C1</smiles>

Scheme 1. The classic Haber-Weiss radical-chain sequence mechanism proposed for the oxidation of cyclohexene by NiO/MCM-41 nanocomposites, based on the research of Weiner, etc. ${ }^{31,32}$

As shown in table 2, with increasing reaction temperature from $220^{\circ} \mathrm{C}$ to $310^{\circ} \mathrm{C}$, the conversion of cyclohexene increases, which indicates that high temperature is of advantage to step a in scheme 1 .

\section{Conclusions}

The present work showed the results of synthesis, characterization and application of $\mathrm{NiO}$ nanoparticles supported on mesoporous MCM-41 in the oxidation of cyclohexene with air, in the absence of any solvent, reducing agent and co-catalyst. The catalysts possess particular nanostructure and excellent function and can be easily separated after the reaction, which endow mesoporous MCM-41-supported $\mathrm{NiO}$ with a bright future in industrial applications. In view of the conversion percent of cyclohexene and selectivity of the 2-cyclohexene-1-ol/2-cyclohexene-1-one, the optimum condition is 5 wt.\% NiO/MCM-41 nanocomposites in $\mathrm{P}=1 \mathrm{~atm}, \mathrm{~T}=280^{\circ} \mathrm{C}$ and space velocity of $3027 \mathrm{~h}^{-1}$.

\section{Acknowledgements}

The authors are grateful to the Research Council of Kazerun and Shahrood branch, Islamic Azad University for financial assistance. 


\section{References}

1. Sheldon R A and Kochi J K 1981 Metal-Catalyzed Oxidation of Organic Compounds (New York: Academic Press)

2. Lyons J E and Parshall G W 1994 Catal. Today 22313

3. Dartt C B and Davis M E 1994 Ind. Eng. Chem. Res. 33 2887

4. Cainelli G and Cardillo G 1984 Chromium Oxidation in Organic Chemistry (Berlin: Springer-Verlag)

5. Wiberg K B 1965 In Oxidation in Organic Chemistry (New York: Academic Press)

6. Waters W A 1964 In Mechanisms of Oxidation of Organic Compounds (London: Methuen).

7. Smith A B and Konopelski J P 1984 J. Org. Chem. 49 4094

8. Wu P, Tatsumi T, Komatsu T and Yashima T 2001 J. Catal. 202245

9. Maurya M R and Kumar A 2006 J. Mol. Catal. A: Chem. 250190

10. Gupta K C and Sutar A K 2008 J. Mol. Catal. A: Chem. 280173

11. Yanagisawa T, Shimizu T, Kuroda K and Kato C 1990 Bull. Chem. Soc. Jpn. 63988

12. Kresge C T, Leonowicz M E, Roth W J, Vartuli J C and Beck J S 1992 Nature 359710

13. Beck J S, Vartuli J C, Roth W J, Leonowicz M E, Kresge C T, Schmitt K D, Chu CT-W, Olson D H, Sheppard E W, McCullen S B, Higgins J B and Schenker J L 1992 J. Am. Chem. Soc. 11410834

14. Selvam P, Bhatia S K and Sonwane C G 2001 Ind. Eng. Chem. Res. 403237

15. Corma A 1997 Top. Catal. 4249

16. Taguchi A and Schuth F 2005 Microporous Mesoporous Mater. 71
17. Patcas F and Hönicke D 2005 Catal. Commun. 6 23

18. Patcas F and Patcas F C 2006 Catal. Today 117253

19. Li Q, Wang L S, Hu B Y, Yang C, Zhou L and Zhang L 1615 Mater. Lett. 61.

20. Bhargava R N 1996 J. Lumin. 7085

21. Clause O, Bonneviot L and Che M 1992 J. Catal. 138 195

22. Sinha A S K and Shankar V 1993 Chem. Eng. J. 52 115

23. Ocana M and Gonzalez-Elipe A R 1999 Colloids Surf. A 157315

24. Sadjadi M S, Mozaffari M, Enhessari M and Zare K 2010 Superlattices Microstruct. 47685

25. Bahadur J, Sen D, Mazumder S and Ramanathan S 2008 J. Solid State Chemistry 1811227

26. Liu X M, Zhang X G and Fu S Y 2006 Mater. Res. Bull. 41620

27. Li G J, Huang X X, Shi Y and Guo J K 2001 Mater. Lett. 51325

28. Sakthivel A, Dapurkar S E and Selvam P 2003 Appl. Catal. A: Gen. 246283

29. Costa A A, Ghesti G F, de Macedo J L, Braga V S, Santos M M, Dias J A and Dias S C L 2008 J. Mol. Catal. A: Chem. 282149

30. Wang R-M, Hao C-J, Wang Y-P and Li S-B 1999 J. Mol. Catal. A: Chem. 147173

31. Weiner H, Trovarelli A and Finke R G $2003 \mathrm{~J}$. Mol. Catal. A: Chem. 191253

32. Hayashi T, Tanaka K and Haruta M 1998 J. Catal. 178 566

33. Liu Y, Murata K, Inaba M, Nakajima H, Koya M and Tomokuni K 2004 Chem. Lett. 33200

34. Yang Z W, Kang Q X, Ma H C, Li C L and Lei Z Q 2004 J. Mol. Catal. A: Chem. 213169 